Research

Open Access

\title{
Chest computed tomography with multiplanar reformatted images for diagnosing traumatic bronchial rupture: a case report
}

\author{
Morgan Le Guen ${ }^{1}$, Catherine Beigelman², Belaid Bouhemad ${ }^{1}$, Yang Wenjïe ${ }^{2}$, Frederic Marmion ${ }^{1}$ \\ and Jean-Jacques Rouby 1
}

\begin{abstract}
1Department of Anesthesiology and Critical Care Medicine, Surgical Intensive Care Unit Pierre Viars and the Trauma Center, La Pitié-Salpêtrière Hospital, Assistance Publique Hôpitaux de Paris, University Pierre et Marie Curie Paris-6, France

${ }^{2}$ Department of Radiology, Surgical Intensive Care Unit Pierre Viars and the Trauma Center, La Pitié-Salpêtrière Hospital, Assistance Publique Hôpitaux de Paris, University Pierre et Marie Curie Paris-6, France
\end{abstract}

Corresponding author: Morgan Le Guen, morgan.le-guen@psl.aphp.fr

Received: 5 Jan 2007 Revisions requested: 5 Jul 2007 Revisions received: 24 Jul 2007 Accepted: 3 Sep 2007 Published: 3 Sep 2007

Critical Care 2007, 11:R94 (doi:10.1186/cc6109)

This article is online at: http://ccforum.com/content/11/5/R94

(c) 2007 Le Guen et al.; licensee BioMed Central Ltd.

This is an Open Access article distributed under the terms of the Creative Commons Attribution License (http://creativecommons.org/licenses/by/ 2.0), which permits unrestricted use, distribution, and reproduction in any medium, provided the original work is properly cited.

\begin{abstract}
Introduction Unnoticed bronchial injury during the early stage of resuscitation of multiple trauma is not rare and increases mortality and morbidity.

Methods Three-dimensional reconstruction of the airways using a workstation connected to a multidetector chest computed tomography (CT) scanner may change the diagnostic strategy in patients with blunt chest trauma with clinical signs evocative of bronchial rupture.
\end{abstract}

Results In this case report of a young motor biker, a complete disruption of the intermediary trunk was first misdiagnosed using standard chest helical CT and bronchoscopy. Postprocessing procedures including three-dimensional extraction of the tracheobronchial tree were determinants for establishing the diagnosis, and emergent surgical repair was successfully performed. Follow-up using CT with three-dimensional reconstructions evidenced a bronchial stenosis located at the site of the rupture.

Conclusion The present study demonstrates the potential interest of performing three-dimensional reconstructions by extraction of the tracheal-bronchial tree in patients with severe blunt chest trauma suspected of bronchial rupture.

\section{Introduction}

Tracheobronchial injuries, although rarely observed following blunt chest trauma [1-3], are associated with a mortality ranging between $9 \%$ and $30 \%$ [3-5]. Traumatic injury of the airways is suspected in the presence of subcutaneous cervical emphysema expanding with mechanical ventilation, pneumomediastinum and recurrent pneumothorax due to a persisting air leak [6]. To date, tracheobronchoscopy remains the reference diagnostic tool [1,6-11]. The procedure, however, is accurate only when performed by trained thoracic or trauma surgeons and pneumologists [7,12]. Moreover, the tracheobronchial injury may be very difficult to diagnose even by an experienced practitioner. As a consequence, tracheobronchial injury may go unnoticed during the early stage of resuscitation and can lead to increased mortality [5] and morbidity through recurrent pneumonia, mediastinitis and atelectasis delaying the mechanical ventilation withdrawal $[8,13]$.
Chest computed tomography (CT) is considered the more relevant diagnostic tool in hemodynamically stable patients with blunt chest trauma following the basic and essential chest $X$ ray scan. CT has a significant therapeutic impact [14]. Multidetector CT provides high spatial resolution images of the whole lung without any anatomical gap. The postprocessing procedure mainly requires a minimum-intensity projection technique for airway imaging. The technique consists of projecting the voxels with the lowest attenuation value in every view through the volume explored, at various angles depending on the airway involved. If tracheobronchial injury is suspected, three-dimensional (3D) extraction of the airways may be useful by focusing the $3 D$ volume-rendering technique on the tracheobronchial tree. This technique is classically used for analyzing stenosis or distortion of the tracheobronchial tree but may also allow the diagnosis of tracheobronchial injury by demonstrating a wall defect and/or an abnormal position of

$\overline{\mathrm{CT}}=$ computed tomography; $3 \mathrm{D}=$ three-dimensional. 
lobar and segmental bronchi [15]. Surprisingly, reports on the use of CT for diagnosing traumatic tracheobronchial rupture are scarce [16-18] and show disappointing results [16].

The present clinical report demonstrates that chest CT with 3D reconstruction of the tracheobronchial tree may be of unique value for the emergency diagnosis of bronchial rupture.

\section{Case report}

A 19-year-old motor biker was involved in a high-velocity accident against a fixed obstacle. At the scene, the patient was unconscious (Coma Glasgow Scale $=5 / 15$ ) and severely hypoxemic (oxygen saturation $=80 \%$ ) with a cervicothoracic emphysema. The patient was intubated, mechanically ventilated and transported to our Level I Trauma Centre. As shown in Figure 1, bedside frontal chest radiography showed bilateral and compressive pneumothorax, pneumomediastinum and extensive subcutaneous emphysema. Arterial oxygenation immediately improved following emergency chest tube placement, and a new chest radiography showed incomplete reexpansion of the right lung with a persistent air leak despite continuous suction.

The patient was then transported to the Department of Radiology for a total body scan (16 slices; Lightspeed GE, General Electric, Milwaukee, WI, United States of America)). The following injuries were diagnosed: brain damage, related to a left parietal contusion with mild subarachnoid hemorrhage (Fisher II); and bilateral pneumothorax with a small hemothorax predominating on the left side, pneumomediastinum, pulmonary interstitial emphysema (Macklin effect [19]), pneumopericar-

\section{Figure 1}

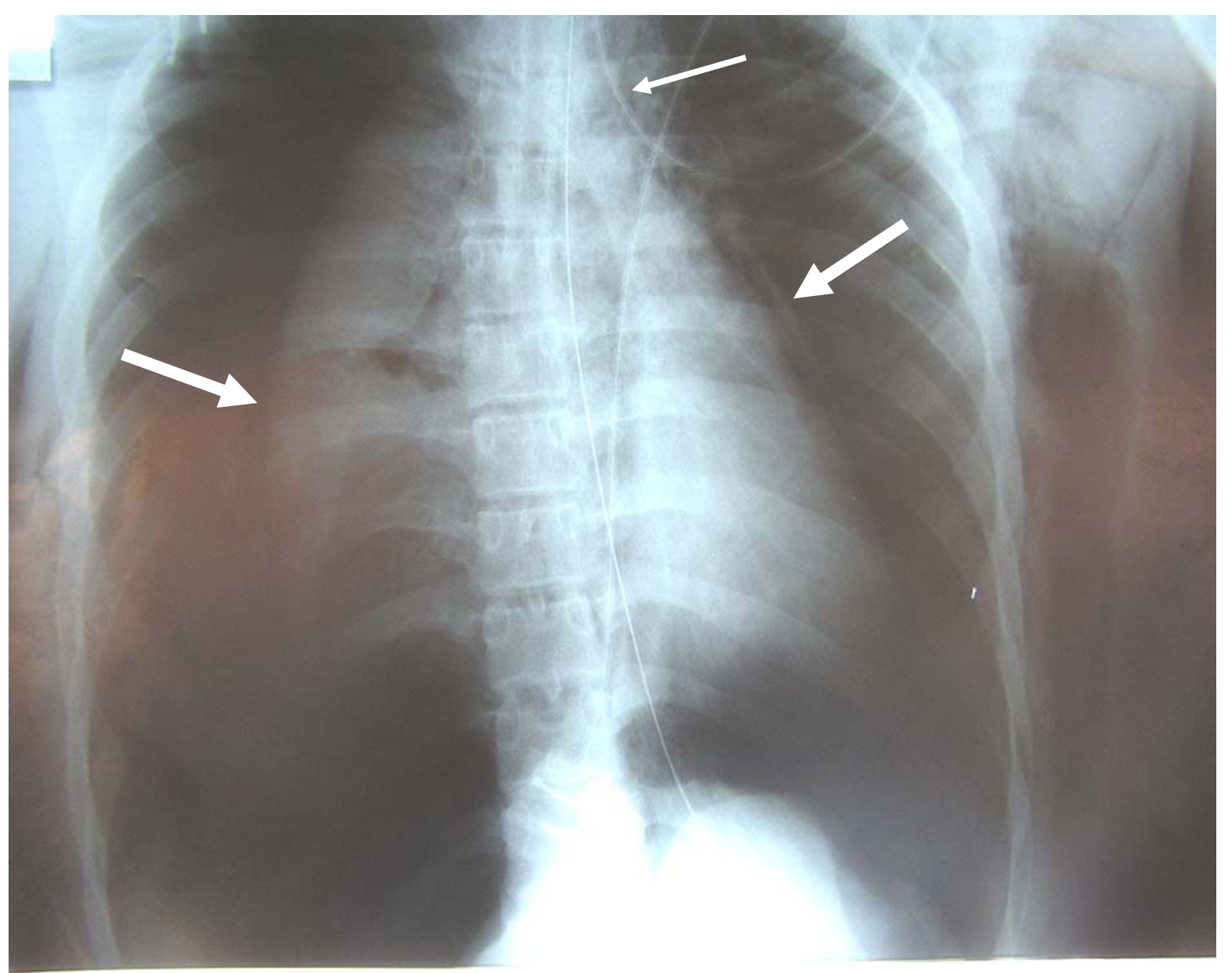

Bedside chest radiography performed immediately after admission. Bilateral pneumothorax (large arrows), pneumomediastinum (thin arrows) and extensive subcutaneous emphysema are visible. 
dium, subcutaneous emphysema and multiple rib fractures (Figure 2). It has to be pointed out that the right-upper-lobe bronchus was displaced posteriorly without a characteristic CT fallen sign as described by Tack and colleagues [18]. Other concomitant injuries were: myocardial contusion, diagnosed as the presence of sinus tachycardia with an anterior and septal elevation of the ST-segment on EKG (electrocardiogram) and an initial cardiac troponin I value of $10.25 \mathrm{IU}$ (normal value, $<0.04 \mathrm{IU})$; fracture of the first thoracic vertebra without neurological consequence; and right femoral fracture. Orthopedic surgical repair was performed without delay.

Tracheobronchial injury was suspected because the bedside chest radiography performed after orthopedic surgery showed persisting right apical pneumothorax with continuous air leakage and extensive cervicothoracic emphysema. The diagnosis, however, could not be confirmed by bronchoscopy because of the rapid drop in oxygen saturation and the abundant bleeding of the respiratory tract. Consequently, a new CT scan was performed using a technique specifically aimed at visualizing the airways. After contrast material injection, $1.25 \mathrm{~mm}$ CT sections at $0.6 \mathrm{~mm}$ intervals were acquired and 3D images were obtained following multiplanar reformation.

The axial slice demonstrated a parietal defect of the posterior wall of the intermediate trunk (Figure 3). Multiple oblique reformations of the right lung and $3 \mathrm{D}$ reconstruction of the airways brought definitive evidence of a complete right bronchial disruption just below the origin of the upper right bronchus associated with a partial collapse of the right-middle lobe and of the right-lower lobe (Figure 4). A surgical procedure was decided

\section{Figure 2}
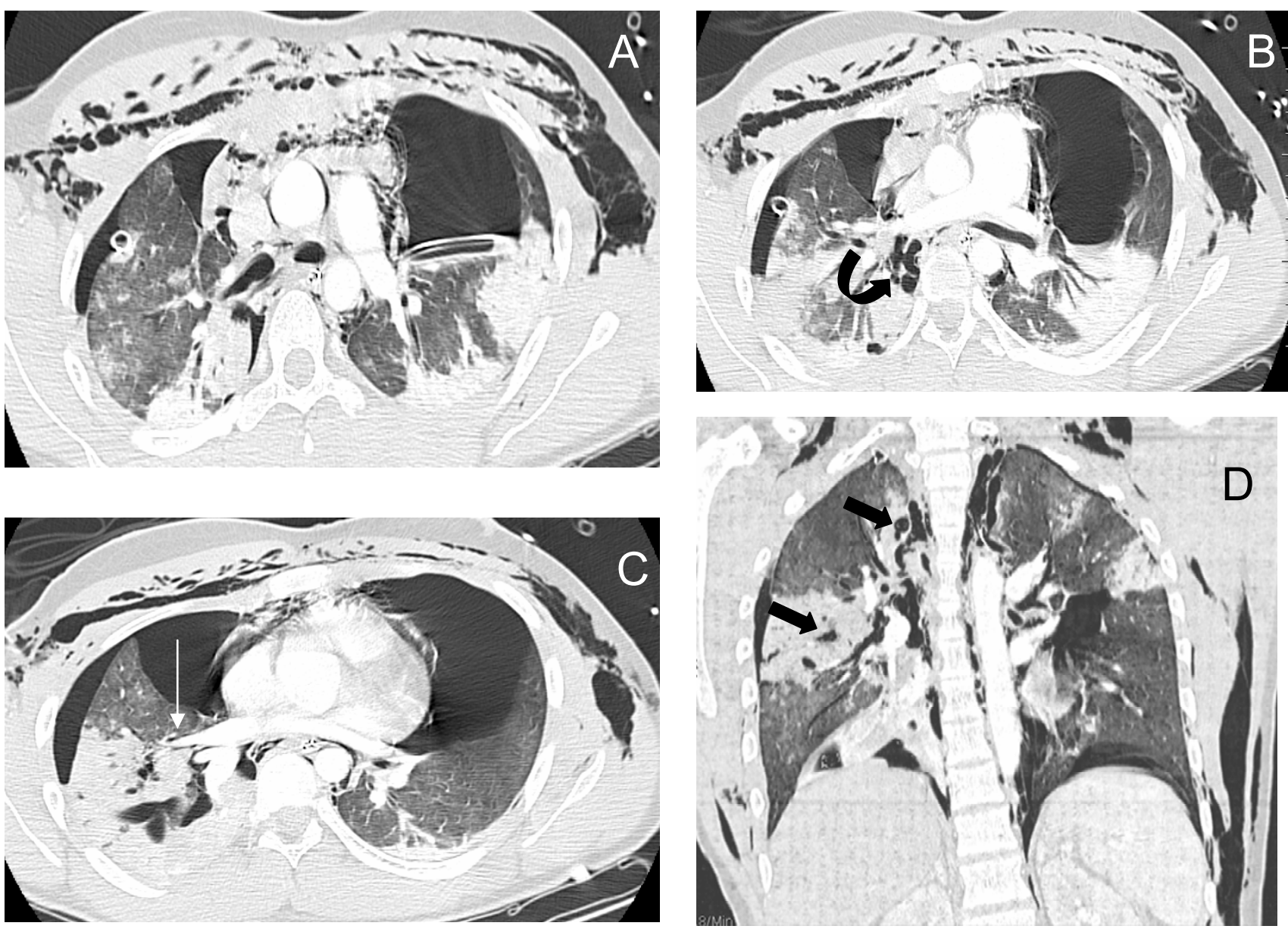

Computed tomography scan following emergency chest tube drainage. Axial $1.25 \mathrm{~mm}$ thick sections with a lung window. (a) Persistent bilateral pneumothorax, pneumomediastinum and extensive subcutaneous emphysema. (b) Multiple lucencies around the right bronchial tree (curved arrow) precluding the correct recognition of the bronchial rupture. (c) The Macklin effect around the right lower pulmonary vein (white arrow). (d) Coronal view demonstrating multiple areas of alveolar consolidation in the right upper and lower lobes: intraparenchymal lucencies resulting from lung lacerations are visible on the right side (thick arrows). 
upon, and confirmed a complete disruption of the right bronchus immediately below the origin of the right upper bronchus with an atelectasis of the right middle and inferior lobes. Endto-end anastomosis of the disrupted bronchus was performed through a right thoracotomy and resulted in an immediate reaeration of the lower lobe, a cessation of the air leak through the right chest tube and a rapid regression of the subcutaneous emphysema, whereas the right-middle lobe remained atelectatic. The decision to perform anastomosis rather than lung resection was based on the patient's young age, the early diagnosis ( $<24$ hours) and the quality of bronchial tissue. Because an anatomical sleeve was present keeping the lower lobe partially aerated, a re-aeration of the middle lobe was expected after re-establishing bronchial continuity.

A bronchoscopy performed on the second postoperative day demonstrated a watertight suture with local inflammation. The postoperative course was complicated by early ventilatorassociated pneumonia caused by Escherichia coli leading to acute respiratory distress syndrome. Mechanical ventilation with a limited tidal volume, a limited peak airway pressure and a limited positive end expiratory pressure was delivered according to recent recommendations [20-22]. A second ventilator-associated pneumonia caused by Pseudomonas aeruginosa delayed withdrawal of the patient from mechanical ventilation, which was successfully achieved on day 18 .
A new CT scan was performed on day 22, before the patient left the intensive care unit. Transversal CT sections demonstrated a normal aeration of the right lung whereas 3D reconstruction of the airways demonstrated a short but tight bronchial stenosis located at the site of the initial rupture (Figure 5). In the absence of new respiratory symptoms, prolonged medical supervision was decided upon and the patient left the intensive care unit on day $\mathbf{2 8}$ for a rehabilitation center.

\section{Results and discussion}

Although always symptomatic [23], tracheobronchial injury is a rare entity, not easy to diagnose. The lack of specificity of subcutaneous emphysema, stridor, bronchopleural fistula, pneumomediastinum, hemoptysis, pneumothorax and the occult nature of the injury frequently result in a delayed diagnosis. In addition, associated injuries such as head trauma [24] can mask the diagnosis in the early period following hospital admission, and emergency surgical procedures may also interfere with the diagnostic procedures.

Among all clinical and radiological signs that are frequently observed in tracheobronchial rupture $[10,14,25,26]$, the simultaneous presence of pneumomediastinum and cervical emphysema appears to be the most frequent association [27]. In a retrospective series of 14 patients with confirmed tracheal disruption, the association was observed in each individual patient [27]. In patients with tracheal rupture, the pneumome-

\section{Figure 3}

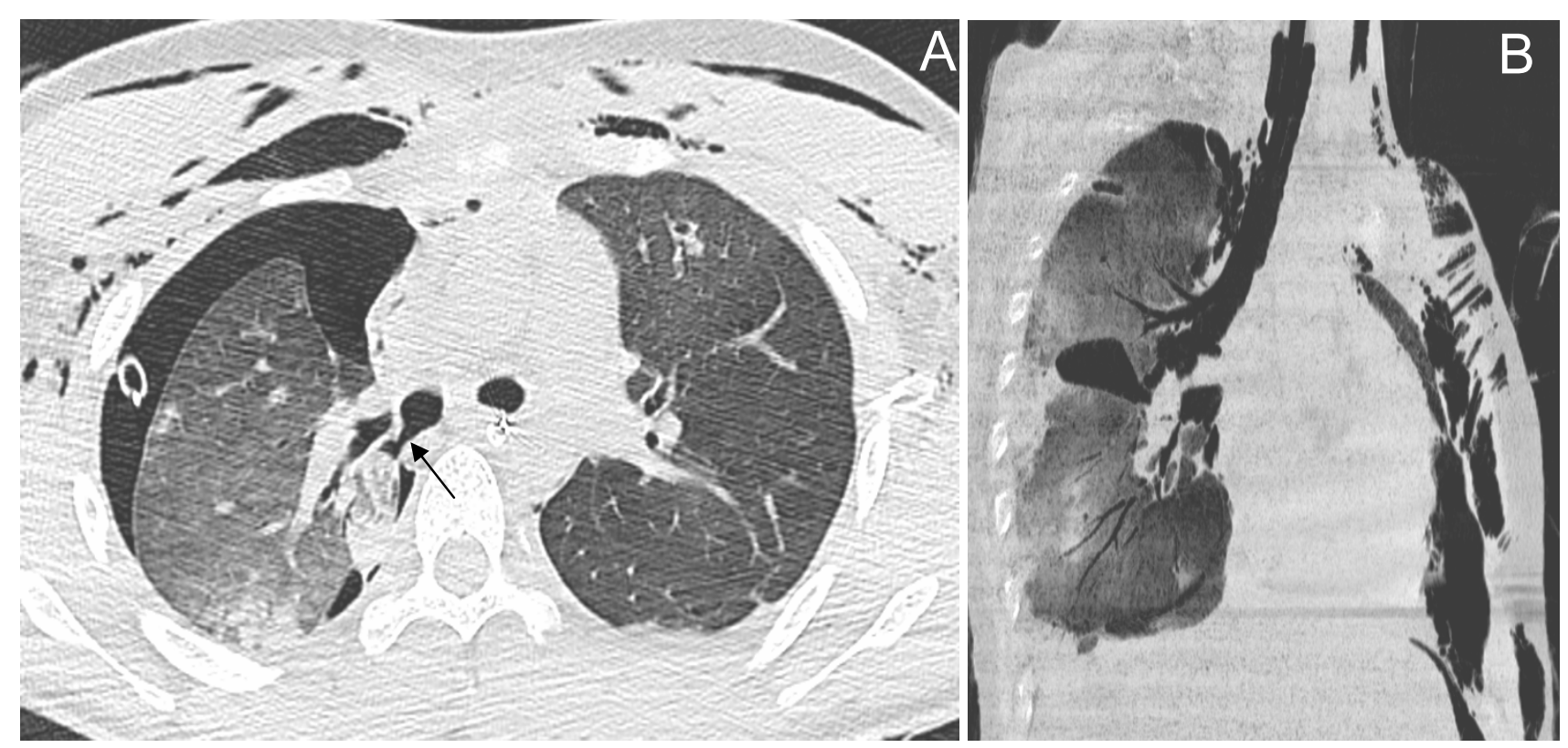

Second thoracic computed tomography scan on day 2 (axial and oblique views). (a) The intermediate trunk is disrupted with a visible posterior wall defect below the origin of the right upper lobe bronchus (arrow). Note the persisting right pneumothorax despite adequate chest tube drainage. (b) An abnormal lucency raising the possibility of a bronchial disruption is seen on the oblique view. 

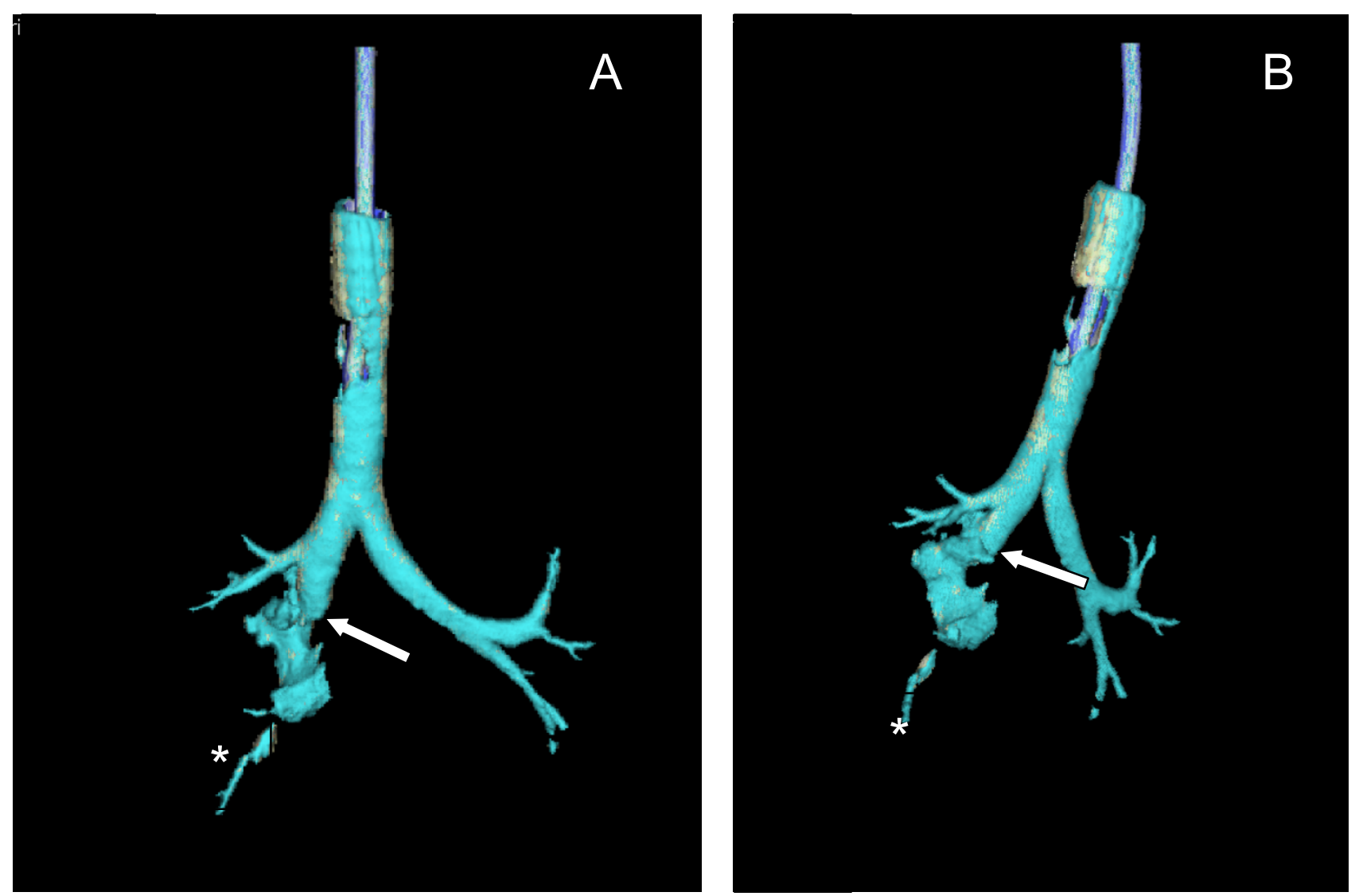

Coronal and oblique views of three-dimensional reconstructions of the tracheobronchial tree. The (a) coronal and (b) oblique views demonstrate the disruption of the intermediary trunk with an abnormal lucency connected to it (white arrow) and show the partial visualization of segmental branches of the right-lower-lobe bronchus $\left(^{*}\right)$.

diastinum results directly from the tracheal air leak. In the present case report, the pneumomediastinum was related to the bronchial rupture into the hilum with a retrograde dissection into the mediastinum. Logically, tracheobronchial rupture should not be associated with pulmonary interstitial emphysema, a radiological sign resulting from alveolar ruptures at the lung periphery [28]. In the present clinical report, a Macklin effect was observed on the initial CT scan, suggesting a peripheral lung barotrauma rather than a bronchial disruption. This finding is in accordance with a previous study that reported the presence of a Macklin effect in a patient with tracheobronchial injury [19], and suggests that alveolar barotrauma and tracheobronchial rupture might be associated in patients with severe blunt chest trauma.

Most trauma centers agree that the diagnosis of tracheobronchial rupture should be confirmed before undertaking surgical repair. Ideally, bronchoscopy preceded by rigid bronchoscopy for clearing blood and secretions from the aiways remains the reference diagnostic tool in patients with blunt chest trauma [10,29-31]. Indeed, airway injuries are mainly located on the initial part of the respiratory track: $19 \%$ of ruptures are purely tracheal and $76 \%$ are exclusively bronchial, either on the right main stem bronchus (47\%) or on the left main stem bronchus (32\%) [5]. Bronchoscopy, however, and even more rigid bronchoscopy, is a procedure that requires specific skills, and therefore is not always and easily available under emergency conditions. Endotracheal intubation often precludes the use of rigid bronchoscopy, limiting the procedure and as a consequence limiting bronchoscopy. In the present clinical report, rigid bronchoscopy was not available at admission and the patient was intubated. Although bronchoscopy was performed by an experienced physician, the technical conditions of the procedure were precarious, characterized by abundant bleeding of the respiratory tract and a rapid drop of arterial oxygen saturation, all factors that precluded diagnostic confirmation.

A second lung CT scan was then performed with thinner sections to optimize under specific technical conditions the 3D extraction of the tracheobronchial tree reconstruction (Figure 3). To our knowledge, the present clinical case reports for the first time a right bronchial rupture that could be easily diagnosed using CT 3D reconstruction. In the immediate postinjury period, between $30 \%$ and $68 \%$ of tracheobronchial ruptures 

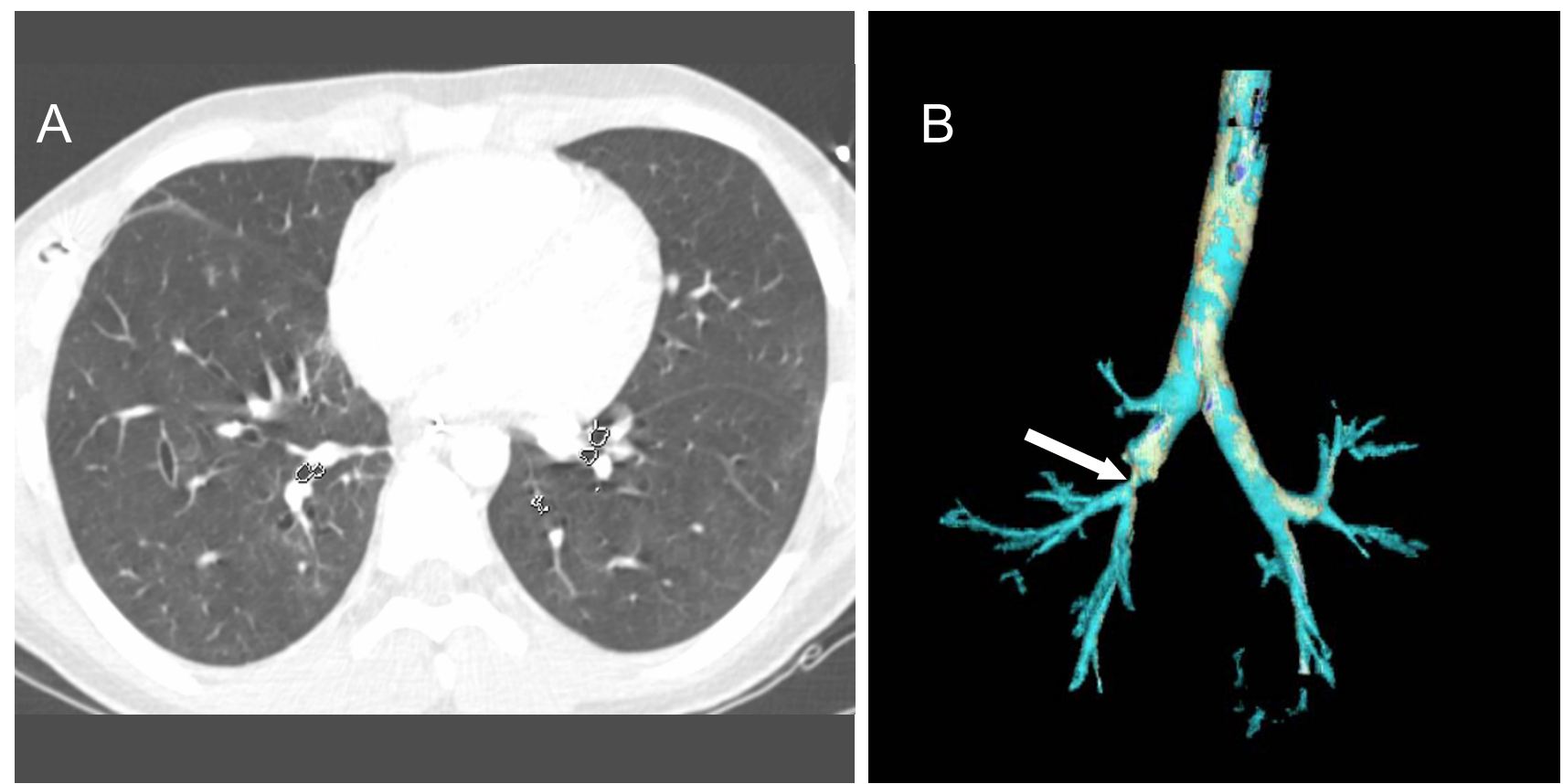

Computed tomography scan performed 2 weeks following surgery. (a) Complete recovery of the pulmonary contusion (axial slice at the level of the lower lobes). (b) The three-dimensional reconstruction of the tracheobronchial tree, however, demonstrates a bronchial stenosis (white arrow) at the site of surgical repair.

are overlooked by conventional radiographies [32,33]. A few studies have suggested that conventional axial two-dimensional CT is superior to conventional radiographs for diagnosing tracheobronchial rupture [27,34-36]. Two-dimensional CT may evidence pneumomediastinum unsuspected on conventional radiographies, is the reference radiological tool for diagnosing the Macklin effect, and has, theoretically, the ability to identify the site of the tracheobronchial tear $[18,27,35]$.

In a retrospective series of 14 patients with tracheal rupture, the tracheal wall injury was directly visualized on CT as a wall defect or discontinuity in $57 \%$ of patients and was indirectly suspected as a tracheal wall deformity in 14\% of patients [27]. In fact, reading of axial CT sections by the radiologist requires extensive mental integration and remains challenging even for the experienced practitioner, especially when multiple abnormal lucencies are present. As much as $25 \%$ of tracheal ruptures remain undiagnosed using conventional axial CT sections. As previously reported [16], it was impossible for the radiologist to definitively assert the diagnosis of right bronchial rupture on the first CT scan performed in our patient, despite the volumetric acquisition with thin slices on the lung window and multiple reformats. Finally, the diagnosis was made thanks to $3 \mathrm{D}$ reconstruction.

In patients with blunt chest trauma and subcutaneous emphysema, with pneumomediastinum, with interstitial pulmonary edema, with 'fallen lung sign' $[18,35]$ and/or with persistent pneumothorax despite adequate drainage [16], we propose the following diagnostic algorithm. A thin-slice CT scan of the chest should be the initial screening tool. If the CT findings are 'evocative' on the axial images, the images should then undergo reformatting and volume subtraction techniques to better define the airway in three dimensions and to rule out artifacts of imaging presenting as 'abnormal lucencies'. If the findings on the reformatted images are still suspicious, or even 'obvious', then the patient should undergo the gold standard test of bronchoscopy. It may be difficult to perform this test in certain patients with airway compromise, but every effort should be made to do so before the patient is subjected to a thoracotomy purely based on the findings of a CT scan reconstruction. One should keep in mind that motion artifacts from the lung and the heart may interfere with the interpretation of the images.

In addition to the diagnosis of upper airway injury, helical CT with 3D reconstruction allows the diagnosis of further tracheobronchial stenosis even with low-dose CT [15,37]. In the present clinical report, a bronchial stenosis at the site of surgical repair was diagnosed 3 weeks after surgery (Figure 5). Again, the single simple examination of axial CT sections overlooked the diagnosis.

\section{Conclusion}

The present study demonstrates the interest of performing 3D reconstructions in patients with severe blunt chest trauma and 
with clinical symptoms evocative of bronchial rupture undergoing a multislice CT scan. Such a 3D reconstruction may help the clinician to decide to perform a bronchoscopy, which remains the reference diagnostic technique but appears more invasive and risky for the patient. Until well designed prospective studies comparing CT scans and bronchoscopy results are performed, 3D reconstruction should be considered a suitable 'screening' test in a trauma patient suspected of bronchial rupture.

\section{Key messages}

- Care of multiple trauma patients with blunt chest trauma is complex because it increases the risk of unnoticed lesions.

- Development of new software with a helical chest computer may be of serious help in assessment of the tracheobronchial tree. A trained radiologist's interpretation is important due to possible artifacts.

\section{Competing interests}

The authors declare that they have no competing interests.

\section{Authors' contributions}

MLG suggested, drafted and promoted this case report with FM's help in analyzing the literature. CB and YW took an active part in the diagnosis, and brought knowledge of choosing images and accurate corrections of the whole radiologic comments. BB and J-JR revised the manuscript for important intellectual content. All authors read and approved the final manuscript.

\section{Acknowledgements}

Written consent for publication was obtained from the patient's relative.

\section{References}

1. Bertelsen S, Howitz P: Injuries of the trachea and bronchi. Thorax 1972, 27:188-194.

2. Kirsh MM, Orringer MB, Behrendt DM, Sloan $\mathrm{H}$ : Management of tracheobronchial disruption secondary to nonpenetrating trauma. Ann Thorac Surg 1976, 22:93-101.

3. Huh J, Milliken JC, Chen JC: Management of tracheobronchial injuries following blunt and penetrating trauma. Am Surg 1997, 63:896-899.

4. Kelly JP, Webb WR, Moulder PV, Everson C, Burch BH, Lindsey ES: Management of airway trauma. I: tracheobronchial injuries. Ann Thorac Surg 1985, 40:551-555.

5. Kiser AC, O'Brien SM, Detterbeck FC: Blunt tracheobronchial injuries: treatment and outcomes. Ann Thorac Surg 2001, 71:2059-2065.

6. Baumgartner F, Sheppard B, de Virgilio C, Esrig B, Harrier D, Nelson RJ, Robertson JM: Tracheal and main bronchial disruptions after blunt chest trauma: presentation and management. Ann Thorac Surg 1990, 50:569-574.

7. Hara KS, Prakash UB: Fiberoptic bronchoscopy in the evaluation of acute chest and upper airway trauma. Chest 1989, 96:627-630.

8. Barmada H, Gibbons JR: Tracheobronchial injury in blunt and penetrating chest trauma. Chest 1994, 106:74-78.

9. Ketai L, Brandt MM, Schermer C: Nonaortic mediastinal injuries from blunt chest trauma. J Thorac Imaging 2000, 15:120-127.

10. Mussi A, Ambrogi MC, Ribechini A, Lucchi M, Menoni F, Angeletti CA: Acute major airway injuries: clinical features and manage- ment. Eur J Cardiothorac Surg 2001, 20:46-51. discussion 5152

11. Tcherveniakov $A$, Tchalakov $P$, Tcherveniakov $P$ : Traumatic and iatrogenic lesions of the trachea and bronchi. Eur J Cardiothorac Surg 2001, 19:19-24.

12. Grant WJ, Meyers RL, Jaffe RL, Johnson DG: Tracheobronchial injuries after blunt chest trauma in children - hidden pathology. J Pediatr Surg 1998, 33:1707-1711.

13. Cassada DC, Munyikwa MP, Moniz MP, Dieter RA, Schuchmann GF, Enderson BL: Acute injuries of the trachea and major bronchi: importance of early diagnosis. Ann Thorac Surg 2000, 69:1563-1567.

14. Trupka A, Waydhas C, Hallfeldt KK, Nast-Kolb D, Pfeifer KJ, Schweiberer $\mathrm{L}$ : Value of thoracic computed tomography in the first assessment of severely injured patients with blunt chest trauma: results of a prospective study. J Trauma 1997, 43:405-411. discussion 411-412

15. Silverman PM, Zeiberg AS, Sessions RB, Troost TR, Davros WJ, Zeman RK: Helical CT of the upper airway: normal and abnormal findings on three-dimensional reconstructed images. $A J R$ Am J Roentgenol 1995, 165:541-546.

16. Kunisch-Hoppe M, Hoppe M, Rauber K, Popella C, Rau WS: Tracheal rupture caused by blunt chest trauma: radiological and clinical features. Eur Radio/ 2000, 10:480-483.

17. Wan YL, Tsai KT, Yeow KM, Tan CF, Wong HF: CT findings of bronchial transection. Am J Emerg Med 1997, 15:176-177.

18. Tack D, Defrance P, Delcour C, Genevois PA: The CT fallen-lung sign. Eur Radiol 2000, 10:719-721.

19. Wintermark M, Schnyder P: The Macklin effect: a frequent etiology for pneumomediastinum in severe blunt chest trauma. Chest 2001, 120:543-547.

20. Rouby JJ, Lu Q, Goldstein I: Selecting the right level of positive end-expiratory pressure in patients with acute respiratory distress syndrome. Am J Respir Crit Care Med 2002, 165:1182-1186.

21. Rouby JJ, Constantin JM, Roberto De A, Girardi C, Zhang M, Lu Q: Mechanical ventilation in patients with acute respiratory distress syndrome. Anesthesiology 2004, 101:228-234.

22. Rouby JJ, Lu Q: Bench-to-bedside review: adjuncts to mechanical ventilation in patients with acute lung injury. Crit Care 2005, 9:465-471.

23. Balci $A E$, Eren N, Eren S, Ulku R: Surgical treatment of posttraumatic tracheobronchial injuries: 14-year experience. Eur J Cardiothorac Surg 2002, 22:984-989.

24. Karaaslan T, Meuli R, Androux R, Duvoisin B, Hessler C, Schnyder $P$ : Traumatic chest lesions in patients with severe head trauma: a comparative study with computed tomography and conventional chest roentgenograms. J Trauma 1995, 39:1081-1086.

25. Spencer JA, Rogers CE, Westaby S: Clinico-radiological correlates in rupture of the major airways. Clin Radiol 1991, 43:371-376

26. Nishiumi N, Maitani F, Yamada S, Kaga K, Iwasaki M, Inokuchi S, Inoue $\mathrm{H}$ : Chest radiography assessment of tracheobronchial disruption associated with blunt chest trauma. J Trauma 2002, 53:372-377.

27. Chen JD, Shanmuganathan K, Mirvis SE, Killeen KL, Dutton RP: Using CT to diagnose tracheal rupture. $A J R A m J$ Roentgenol 2001, 176:1273-1280.

28. Macklin CC: Transport of air along sheath of pulmonic blood vessels from alveoli to mediastinum: clinical implications. Arch Intern Med 1939, 64:913-926.

29. Rossbach MM, Johnson SB, Gomez MA, Sako EY, Miller OL, Calhoon $\mathrm{JH}$ : Management of major tracheobronchial injuries: a 28year experience. Ann Thorac Surg 1998, 65:182-186.

30. Wicky S, Wintermark M, Schnyder P, Capasso P, Denys A: Imaging of blunt chest trauma. Eur Radiol 2000, 10:1524-1538.

31. Ramzy Al, Rodriguez A, Turney SZ: Management of major tracheobronchial ruptures in patients with multiple system trauma. J Trauma 1988, 28:1353-1357.

32. Taskinen SO, Salo JA, Halttunen PE, Sovijarvi AR: Tracheobronchial rupture due to blunt chest trauma: a follow-up study. Ann Thorac Surg 1989, 48:846-849.

33. Stark P: Imaging of tracheobronchial injuries. J Thorac Imaging 1995, 10:206-219.

34. Weir IH, Muller NL, Connell DG: CT diagnosis of bronchial rupture. J Comput Assist Tomogr 1988, 12:1035-1036. 
35. Wintermark M, Schnyder $\mathrm{P}$, Wicky S: Blunt traumatic rupture of a mainstem bronchus: spiral CT demonstration of the 'fallen lung' sign. Eur Radio/ 2001, 11:409-411.

36. Sakai M, Murayama S, Gibo M, Akamine T, Nagata O: Frequent cause of the Macklin effect in spontaneous pneumomediastinum: demonstration by multidetector-row computed tomography. J Comput Assist Tomogr 2006, 30:92-94.

37. Zeiberg AS, Silverman PM, Sessions RB, Troost TR, Davros WJ, Zeman RK: Helical (spiral) CT of the upper airway with threedimensional imaging: technique and clinical assessment. AJR Am J Roentgenol 1996, 166:293-299. 